\title{
Los glifos de suelo en códices acolhua de la Colonia temprana: un reanálisis de su significado*
}

\author{
Aurelio López Corral
}

Este trabajo reanaliza los "glifos de suelo" de cuatro códices acolhua de la Colonia temprana. Dichos glifos se ubican al centro de parcelas agrícolas y han sido vinculados a un sistema clasificatorio indígena de tierras. Sin embargo, en las tipologías previamente establecidas existe una gran variación morfológica que sugiere que distintos significados se han agrupado incorrectamente. Este estudio muestra que, además de suelos, también se registraron otros atributos de cada terreno, por lo que sería más correcto llamarles "glifos de parcela". Probablemente el objetivo fue evitar confusiones en la identificación de propiedades registradas en diferentes momentos y por distintas personas.

PALABRAS CLAVE: glifos de parcela, códices acolhua, Tepetlaoztoc, conjuntos domésticos, agricultura

\section{Soil Glyphs from Early Colonial Acolhua Códices: a Re-Analysis of their Significance}

This paper re-examines the "soil glyphs" from four Early Colonial Acolhua códices. These glyphs were drawn at the center of agricultural plots and have been linked to an indigenous land classificatory system. However, previously established glyph typologies display important morphological variations suggesting that different meanings have been grouped incorrectly. This study shows that, in addition to soils, the glyphs also registered other various land attributes. Thus, it would be more accurate to name them "parcel glyphs". The purpose of employing parcel glyphs was, probably, to avoid confusions in the identification of landholdings registered at different times and by different persons.

KEYWORDS: parcel glyphs, Acolhua códices, Tepetlaoztoc, households, agriculture

Aurelio López Corral: Instituto Nacional de Antropología e Historia, Centro Regional Tlaxcala, Tlaxcala, México aurelio_lopez@inah.gob.mx

Desacatos, núm. 37, septiembre-diciembre 2011, pp. 145-162

Recepción: 18 de octubre de 2008 / Aceptación: 17 de agosto de 2009

\footnotetext{
* No citar sin el consentimiento explícito del autor. Agradezco las sugerencias y comentarios oportunos de Ken Hirth, David Webster, David Carballo, Teresa Rojas y Barbara Williams, así como a los dictaminadores anónimos. Cualquier error en el documento es responsabilidad única del autor.
} 
$\mathrm{H}$ ace más de un siglo Eduard Seler (1904: 209) escribió sobre la presencia de "glifos de suelo" dibujados al centro de parcelas agrícolas en el Fragmento VIII de Humboldt. Determinó que debían corresponder a categorías de tierra descritas en el Libro 11 de Bernardino de Sahagún como atoctlalli - aluvión-, quauhtlalli —suelos estercolados con madera- y contlalli - barro-. Siguiendo esta idea, estudios posteriores sobre propiedades similares registradas en documentos pictóricos de la Colonia temprana de la región de Tezcoco han apoyado y fortalecido este postulado. En específico, se ha determinado que los nahuas del centro de México poseyeron una avanzada clasificación y un complejo sistema de notación de tipos de tierras mediante el uso de "glifos de suelo" (Williams, 1980, 1989, 2006; Williams y Harvey, 1997: 30-34).

El objetivo de este trabajo es hacer un reanálisis de dichos glifos con la finalidad de establecer si, además de tierras, también registraron otros atributos particulares de las parcelas. La idea surgió cuando al examinar las tipologías previas propuestas observé una gran variación morfológica en los elementos que componen cada tipo de glifo. Esto me hizo pensar que en varios casos se agruparon incorrectamente significados distintos. Como preámbulo, este estudio muestra que no todos los glifos hacen referencia a elementos edafológicos, ya que también se anotaron otros atributos, como elementos naturales, culturales, incluso toponímicos. Por ello, considero que al englobar elementos tan variados, los glifos deberían ser vistos como "glifos de parcela", es decir, marcadores de pequeñas porciones de terreno que catastralmente corresponderían a tierras de distintos dueños.

\section{EL MATERIAL DE ANÁLISIS}

Para sustentar mi proposición, analizo los glifos ubicados al centro de parcelas asociadas a jefes de familia de comunidades rurales indígenas presentes en cuatro documentos pictóricos acolhua, agrupados anteriormente en el "Grupo Vergara" (Glass, 1975) o en el "Grupo Tepetlaoztoc" (Nicholson, 1973: 26): el Códice de Santa María Asunción (csma) y el Códice Vergara (cv), ambos de la región de Tepetlaoztoc, Estado de México; el Fragmento vin de Humboldt (FHVIII) y el Fragmento Catastral de la Colección Ramírez (FCCR). Como caso excepcional, añadí dos terrenos del Códice Xólotl (cx) con glifos similares en composición a los ya mencionados. Por supuesto, existen más documentos pictóricos relacionados con la tenencia y categorías de la tierra, como el Códice Florentino (Sahagún, 1963), el Códice Cozcatzin (Castañeda, 2006), el Mapa en Maguey (Calnek, 1973), el Mapa de Tierras de Oztoticpac (Harvey, 1991) y el Códice Xochimilco (Mohar y Fernández, 2006), entre otros. Decidí utilizar los cuatro documentos acolhua porque estilísticamente son más cercanos y presentan el mismo sistema de empadronamiento de terrenos agrícolas.

El CSMA y el CV son registros legales indígenas de tenencia de la tierra elaborados durante la Colonia temprana (Williams y Harvey, 1988). De los cuatro códices analizados, estos dos poseen la mayor cantidad de glifos de parcela. Sin embargo, este trabajo se basa primordialmente en el CSMA porque su contenido es accesible gracias al facsímil publicado por Williams y Harvey (1997). El cv es aún una fuente inédita resguardada en la Bibliothèque Nationale de Paris, por lo que tuve acceso sólo a imágenes publicadas en otros trabajos (Williams, 1980; Williams y Jorge y Jorge, 2001). El FHVIII, el FCCR y los dos terrenos del cx también contienen información valiosa que fue utilizada, en menor medida, para comparar y corroborar las lecturas.

Existe una fuerte similitud en contenido y formato entre el csma y el cv. Ambos registran familias campesinas y sus terrenos agrícolas, aunque no es completamente claro si dichos terrenos fueron propiedad de un calpulli o tlaxilacalli o si corresponden a propiedades rentadas a la nobleza local (Harvey, 1986). En cualquier caso, ambos códices constituyen los registros pictóricos más detallados y extensos sobre comunidades rurales de la Colonia 
temprana y una importante fuente de análisis y comparación de sus estructuras familiares y sistemas de parentesco (Harvey, 1986; Offner, 1984).

Ambos documentos, con el Memorial de los Indios de Tepetlaoztoc (Valle, 1992), derivaron probablemente de litigios tributarios entre encomenderos españoles y comunidades indígenas. El CSMA y el cV están organizados por comunidades, cada una con tres o cuatro secciones que presentan la siguiente información: 1) un registro demográfico o tlacatlacuilolli con datos sobre edad, sexo, número de individuos en cada familia y posiblemente afiliación étnica; 2) documentación relacionada con la extensión territorial y limítrofe de las comunidades; 3 ) un censo llamado milcocolli que muestra el número de parcelas agrícolas que cada familia poseyó - lo que constituye el enfoque de este trabajo-, sus extensiones en tlalquahuitl, ${ }^{1}$ uno o varios glifos al centro de cada parcela y los nombres de los jefes de familia, y 4) un registro llamado tlahuelmatli que presenta casi el mismo tipo de información que el milcocolli, pero proporciona el área de los terrenos en tlalquahuitl cuadrados (Thouvenot, 1998: 69-71; Williams, 1980; Williams y Harvey, 1997). Ambos códices debieron ser manufacturados entre 1539 y 1544, en días o meses y no años porque, entre otras cosas, la tinta de los dibujos no varía mucho, el papel es de vendimia europea y los dibujos del censo doméstico son casi idénticos en todos los registros (Williams y Harvey, 1988; 1997: 3-4).

Barbara Williams y Herbert Harvey (1997) han catalogado los glifos de las parcelas agrícolas del cv y el CSMA como tipos de suelo. Bajo esta premisa, los han clasificado en siete grupos principales y varias subcategorías con base en la descripción de las características y la naturaleza de los suelos y las tierras del Códice Florentino (Sahagún, 1963) y en taxonomías folk de la región de Tepetlaoztoc (Williams, 1972, 2006; Williams y Ortiz-Solorio, 1981). Esta clasificación considera que los glifos describen necesariamente tipos morfológicos de suelo, pero resulta

\footnotetext{
${ }^{1}$ Medida indígena equivalente a dos brazas españolas.
}

problemático que en muchos terrenos no aparezca el elemento "tlalli" o tierra asociado a los glifos. Su omisión puede deberse a que los escribanos supusieron que un lector inteligente entendería el significado o que, dado que los glifos están delimitados por los terrenos, la inclusión de "tierra" está implícita. La dificultad radica en que técnicamente también podríamos utilizar la palabra náhuatl "milli", que aduce a un plantío o heredad, tal y como se muestra en un glifo del Memorial de los Indios de Tepetlaoztoc (Valle, 1992: 154). Otro problema es que en algunas de sus categorías y subcategorías de suelos hay abundante variación pictórica. Por ejemplo, en lo que Williams y Harvey (1997) llaman tlalcoztli o "tierra amarilla", el glifo correspondiente y sus elementos no apuntan a esta palabra náhuatl. Además, hay más diversidad de elementos representados, algunos indicando acciones - soplar, romperse- y otros sólo sustantivos - piedra o arena-, cuyos valores fonéticos sugieren que hay más palabras plasmadas de lo que hasta ahora suponemos.

\section{EL ANÁLISIS DE LOS GLIFOS}

Para la lectura de los glifos analizo cada uno de sus elementos considerando: 1) los nombres deben emplear la misma notación fonética-logográfica presente en otros documentos pictóricos de su época (Manrique Castañeda, 1989; Nicholson, 1973; Peñafiel, 1967), y 2) se pueden descifrar los glifos comparándolos con otros toponímicos o antropónimos escritos en náhuatl y castellano dentro de los mismos códices o en otros documentos contemporáneos. Varios tlacuilos escribieron en los diferentes documentos pero todos utilizaron patrones de escritura estandarizados. Cada glifo se constituye de uno o varios elementos cuya unión es lo que permite leer la palabra o expresión escrita. Los elementos suelen ser objetos o figuras realizando una acción, y su distribución, arreglo, y posición influyen en el significado. A su vez, son estos elementos los que transcriben los valores fonéticos y los que pueden 
corresponder a diversas unidades del lenguaje, como sílabas, raíces o palabras (Thouvenot, 1998).

Para la lectura de los glifos fue necesario descomponerlos en sus elementos constitutivos y a cada uno se le dio una designación de acuerdo con el nombre del objeto en la realidad. Las palabras se generaron mediante la unión de los valores fonéticos de cada elemento. Para la traducción de los términos del náhuatl al castellano me apoyé en los compendios de gramática de Sullivan (1976) y Lockhart (2001), en los diccionarios de Molina (2001), Siméon (1996), Kartunnen (1983), en el programa computacional Temoa (Thouvenot, 1992), en documentos pictográficos como el Códice Mendoza, el Códice Xólotl y el Memorial de los Indios de Tepetlaoztoc (Ross, 1978; Thouvenot, 1998; Valle, 1992), en fuentes etnohistóricas como el Libro 11 del Códice Florentino (Sahagún, 1963) y en mi experiencia con agricultores del centro de México.

\section{LATRANSCRIPCIÓN DE LOS GLIFOS}

Se analizaron 1636 parcelas de los cuatro códices bajo estudio (1 504 del CSMA, 94 del CV, 29 del FHVIII y nueve del FCCR). De ellos, se han podido transcribir 1 549 glifos agrupados en 36 tipos. Para facilitar la presentación, y sólo con fines de organización, los glifos se describen en cuatro categorías: 1) elementos del paisaje, 2) toponímicos o locativos, 3) elementos culturales y 4) de estatus o valor. Estas categorías pueden parecer dispares, pero precisamente esta diversidad en el registro es lo que sobresale y lleva a inferir que el sistema de registro de las parcelas agrícolas no se centró de manera exclusiva en una clasificación de suelos. Por último, en la figura 1 se proporcionan imágenes seleccionadas para ejemplificar las transcripciones de cada tipo de glifo y se da su procedencia e información sobre quién realizó la lectura original. También se incluyen sus frecuencias pero sólo en relación con el total de ejemplares analizados ya que, como mencioné anteriormente, para el cv sólo tuve acceso parcial a imágenes publicadas en otros estudios.

\section{Glifos elementos del paisaje}

En este rubro se ubican glifos que denotan elementos del paisaje, tales como piedras, arenas, gravas, sedimentos, corrientes de agua o plantas. El más simple es xalli (véase figura 1:1), que significa "arena" (Siméon, 1996: 761). Se compone de una serie de puntos en forma de círculo y se refiere a que los terrenos tienen arena. En otros glifos, xalli suele presentarse combinado con otros elementos para formar palabras más complejas. Por ejemplo, un glifo compuesto de una piedra, tetl, y arena, xalli, se lee xaltetl, que quiere decir "guijarro, piedra, grava" (véase figura 1:2) (Siméon, 1996: 540, 762). En otro caso, un glifo del FHVIII se compone de una piedra, tetl, en forma de corazón, yolotl, similar a las usadas para medidas en fracciones (Williams y Jorge y Jorge, 2008), y arena, xalli, por debajo (véase figura 1: 3). Se lee xalteyo, que quiere decir "pedregoso, cubierto de guijarros" (Siméon, 1996: 762). En el CSMA aparece regularmente un glifo compuesto de una sola piedra (véase figura 1: 4). No hay repetición de sonidos ni elementos adicionales. Tampoco parece ser el resultado de omisiones o fallas de escritura. Simplemente indica "piedras comunes" o "piedras redondas" porque tetl también es sinónimo de "huevo" y sirve para contar cosas redondas (Molina, 2001). En un caso aparece el elemento tlan o "lugar abundante en" unido a boca, tentli, (véase figura 1: 5). Se lee tetla o "lugar pedregoso, cubierto de piedras" (Siméon, 1996: 520) y probablemente un terreno situado en malpaís o en zonas escabrosas. 


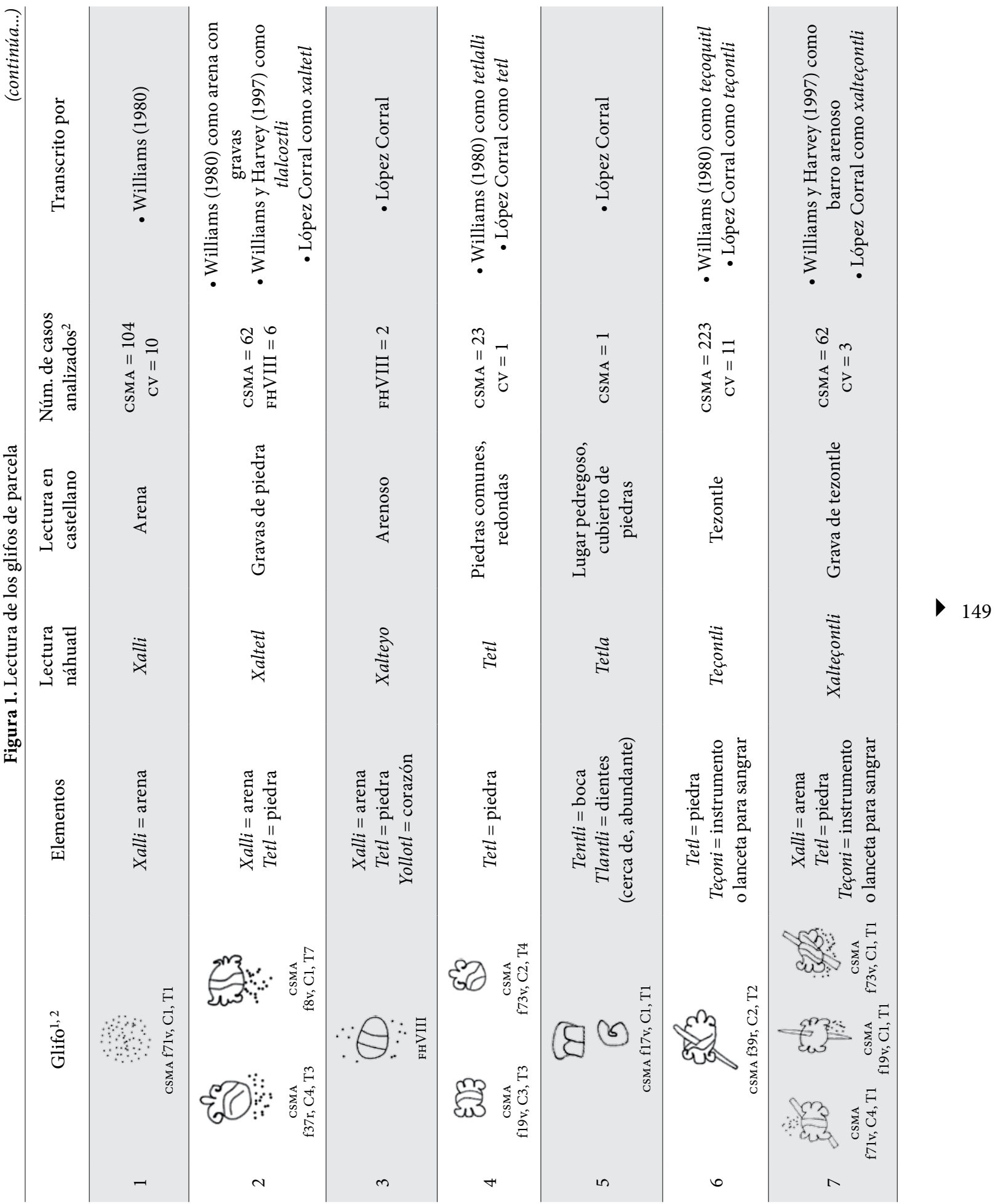




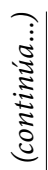

150

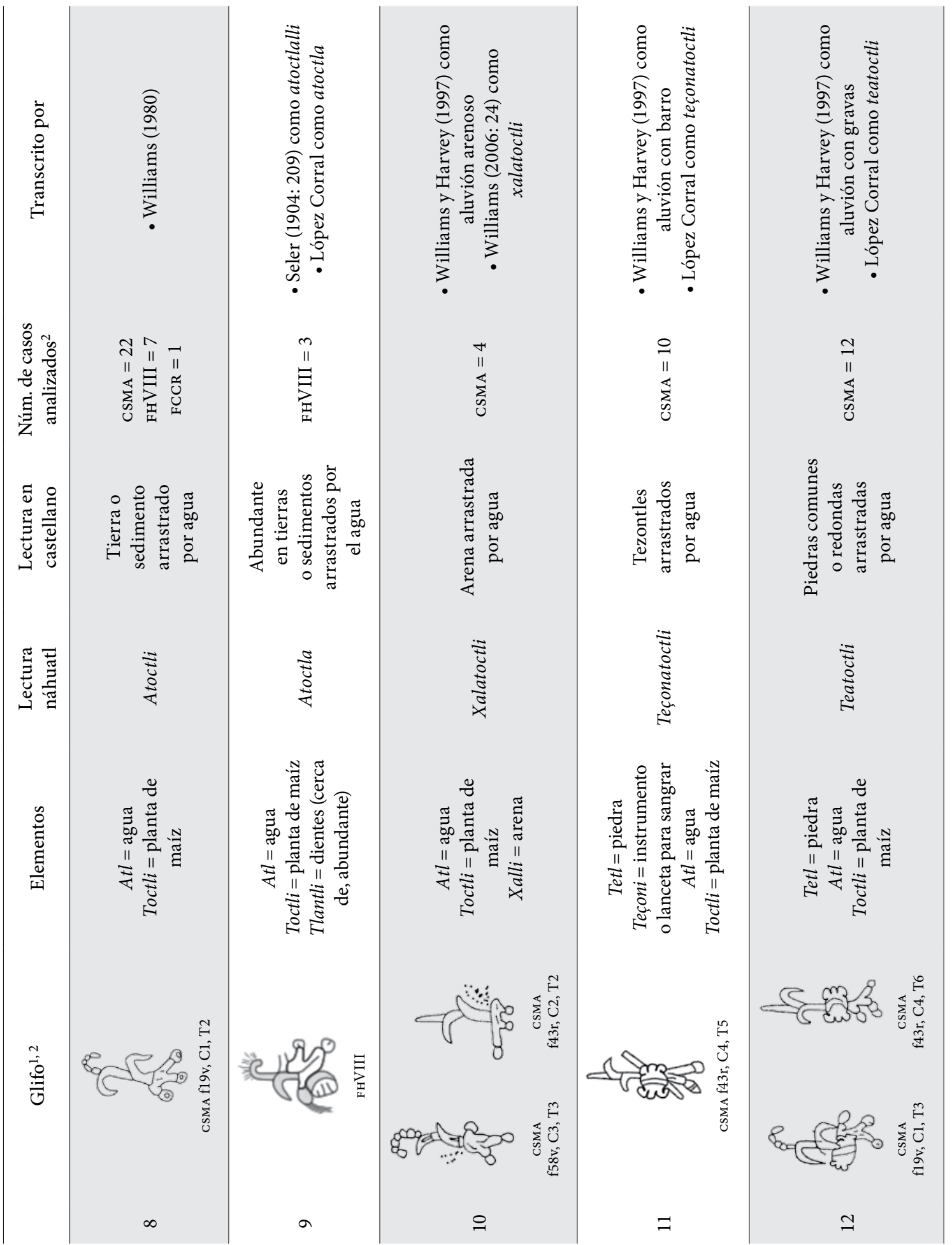



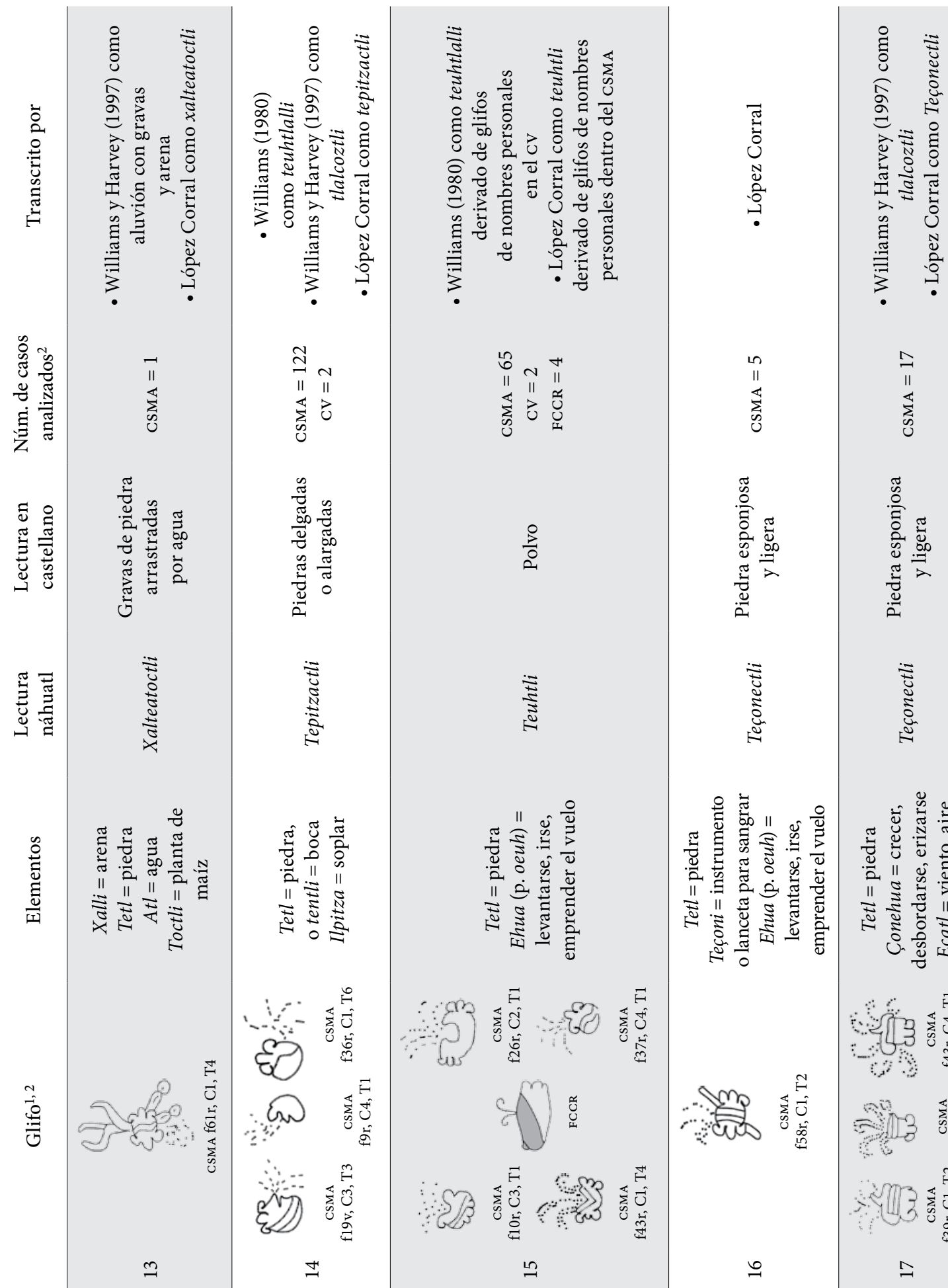

$\frac{3}{3}$

$\bar{\pi}$
$\frac{\pi}{0}$
$\frac{\pi}{n}$
$\frac{\pi}{\pi}$

$\underset{\substack{\pi \\ \frac{\pi}{3}}}{-\pi}$

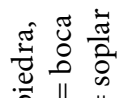

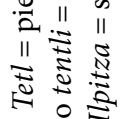

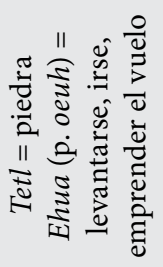

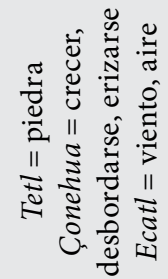

॥

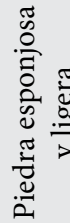

$\ddot{\pi}$

కิ

151 


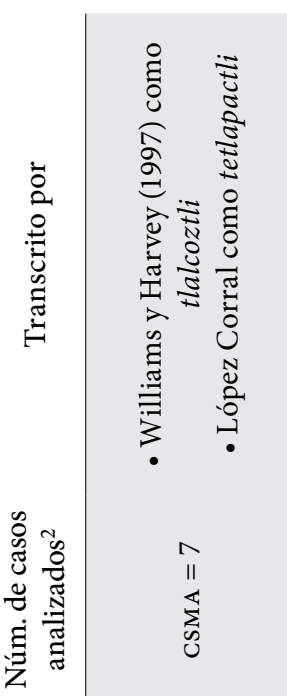

गั

?ั.

\section{:

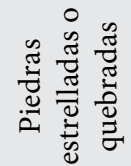

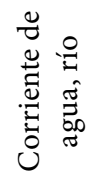
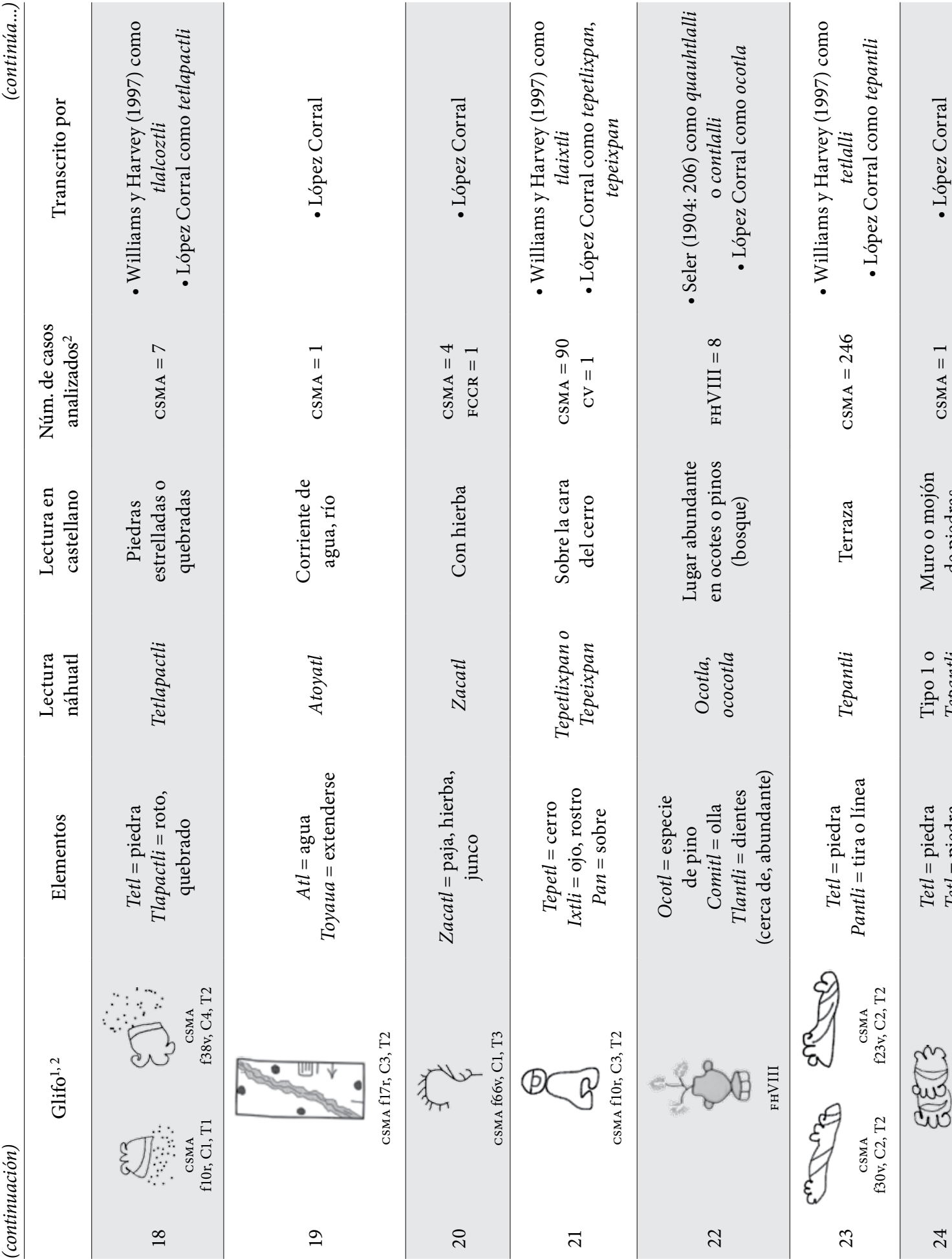

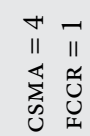

毫

当

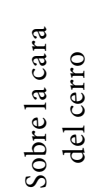

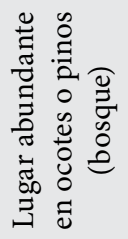

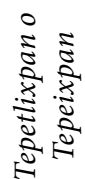

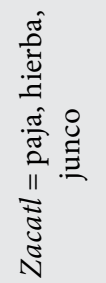

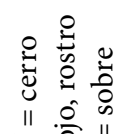

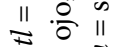

苟

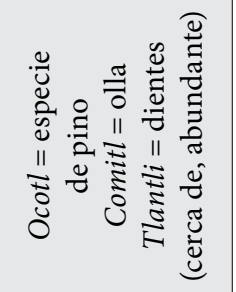

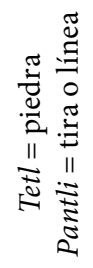

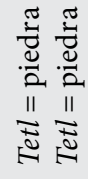

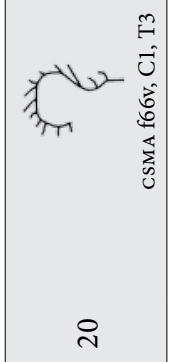

(

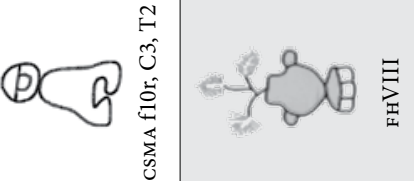

ही

\&)

2)

$\stackrel{\infty}{=}$

$-$ 

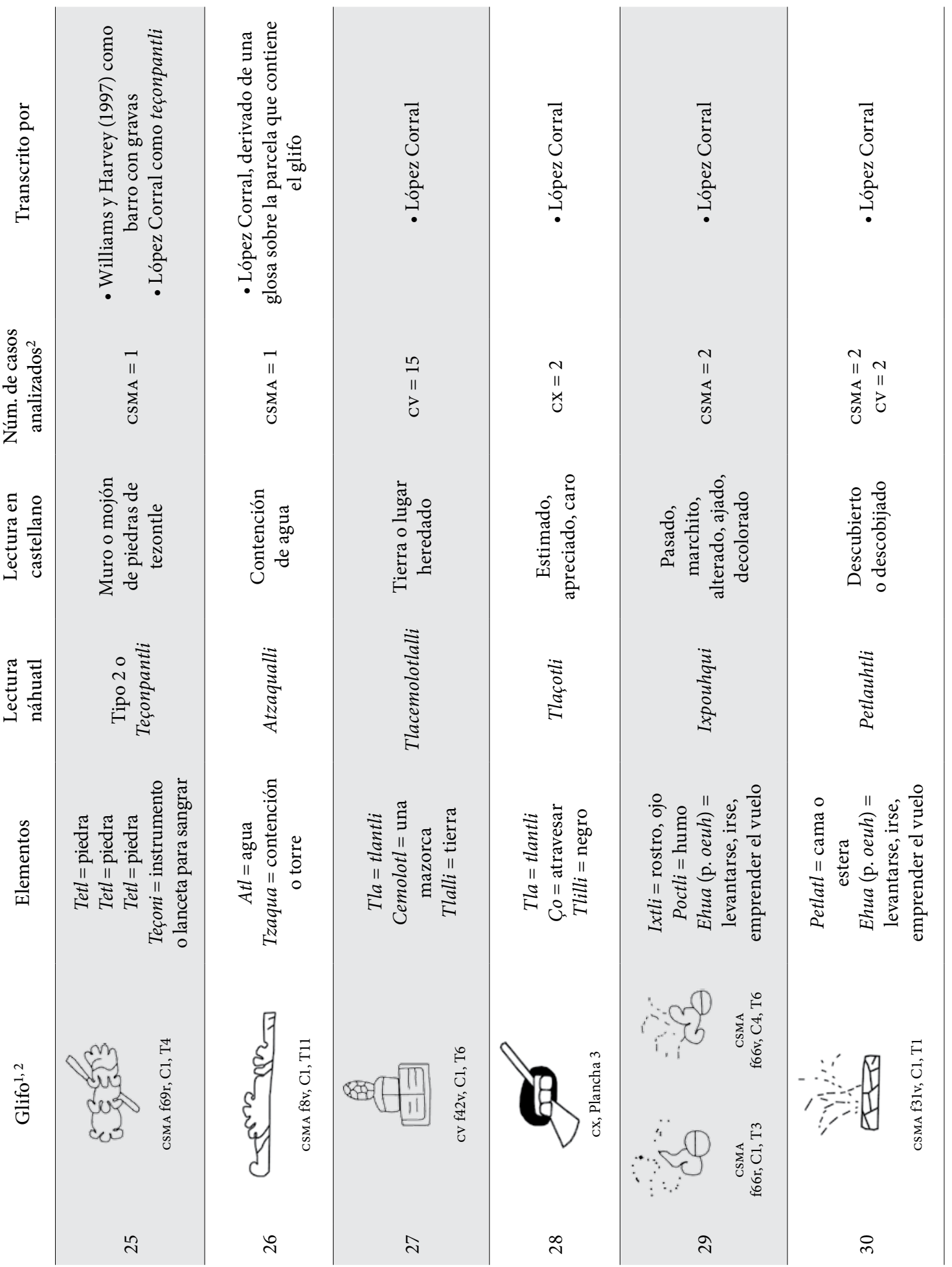


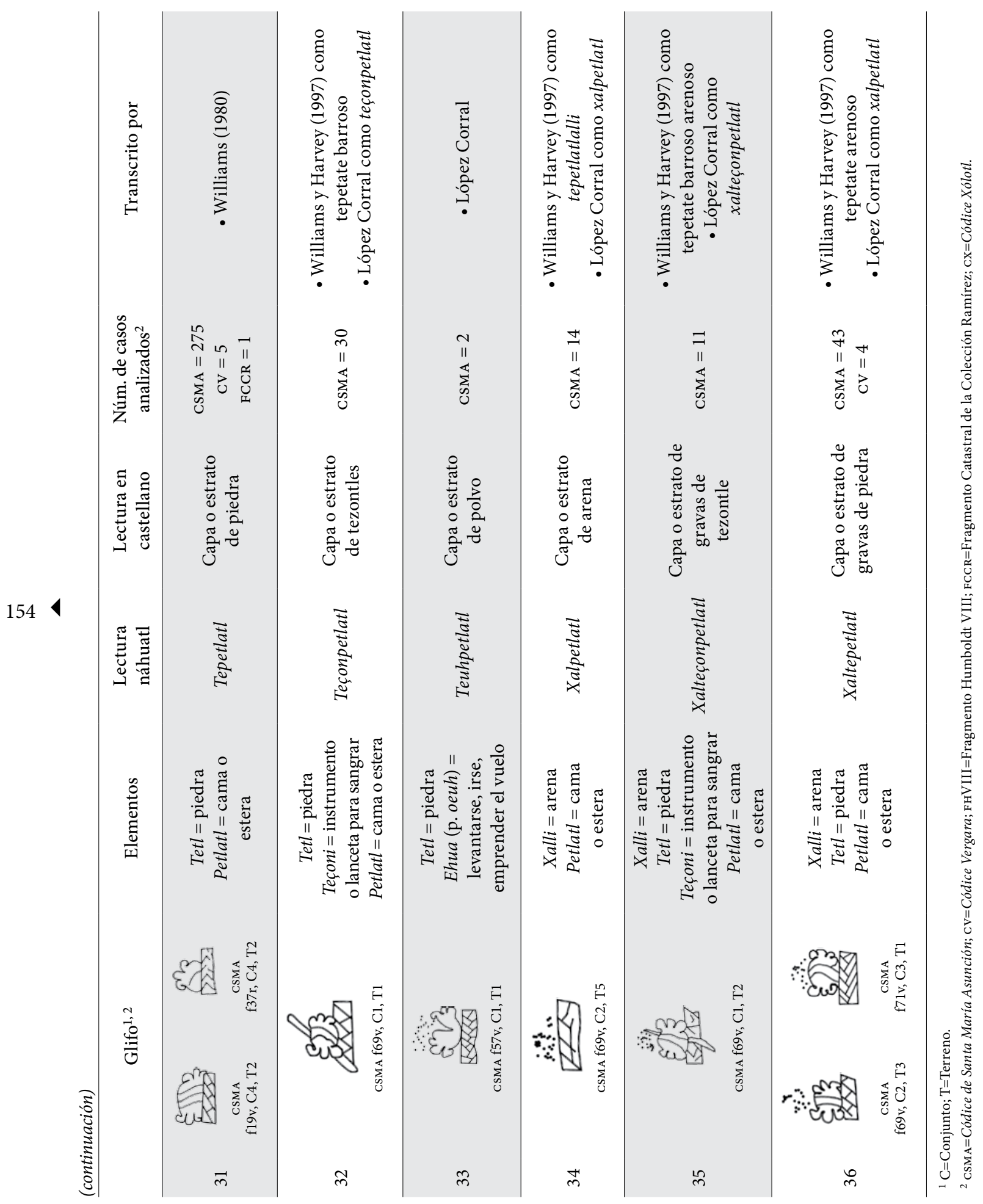


Un glifo polémico se compone de una piedra pinchada por un objeto agudo, quizá una espina (véase figura 1: 6). Aunque recurrente, sólo aparece en el csma y el cv. Podría leerse teçoquitl o "barro duro", derivado de piedra, tetl, y pinchar, ço (Williams, 1980, 1989). Sin embargo, me parece que esta lectura no es la correcta por varias razones. En náhuatl, barro o lodo se dice çoquitl y es la combinación de agua con tierra (Molina, 2001; Sahagún, 1963: 257), como la que se encuentra en zonas cenagosas o en las orillas de lagos y pantanos. Glifos de otros textos que plasman çoquitl, como Çoquitzinco en la Matrícula de Tributos (Berdan y Anawalt, 1992: 71), usan una argamasa o algo similar para representarlo. Por otra parte, teçoquitl se refiere a un barro muy duro empleado para hacer cerámica y no para agricultura (Sahagún, 1963: 252).

Una lectura alterna es considerar al objeto que pincha a la piedra como un teçoni o instrumento a manera de lanceta utilizado para sangrar (Molina, 2001). El elemento tetl o piedra fungiría como confirmador de sonido. El glifo se leería entonces teçontli, o "tezontle", que es una piedra porosa volcánica y liviana de tonalidades gris claro a rojo/café muy común en el altiplano central de México. De la combinación entre un tezontle (teçontli) y arena (xalli) se obtiene xalteçontli o "gravas de tezontle" (véase figura 1:7).

Otro glifo sencillo se compone de agua, atl, unida a una planta de maíz, toctli, y se lee atoctli (véase figura 1: 8). Aparece en los cuatro códices en cuestión, aunque a veces en FHVIII se le añadió tlantli - dientes, abundante en-para leerse atoctla (véase figura 1: 9). Dos glifos similares a atoctli aparecen como nombres personales de individuos del csma. En uno se lee el texto del nombre en castellano como "Diego hohuā" (conjunto 1 del folio 64r) y en el otro como "p ${ }^{\circ}$. tlalohuaquauh" (conjunto 1 del folio 41v). En ambos casos el valor fonético que se le dio a la planta de maíz es el de ohuatl, que significa "caña o tallo de maíz tierno". Sin embargo, me parece que la lectura de este elemento va de acuerdo con el contexto en el que se ubica. En este caso, al describir cosas relacionadas al paisaje como terrenos agrícolas, probablemente el valor fonético correcto debe ser toctli.

El Códice Florentino (Sahagún, 1963: 251, lib. 11) indica que atoctli viene de at - agua - y totoca - que corre-. Atoctli debe aludir a terrenos con suelos formados por arrastre que podrían ser tierras de aluvión pero también sedimentos erosionados y contenidos en terrazas. Fonéticamente el glifo no implica presencia alguna de irrigación o suelos irrigados. Atoctli es combinado comúnmente con otros glifos para formar palabras como xalatoctli - arenas arrastradas-, teçonatoctli - tezontles arrastrados-, teatoctli - piedras comunes arrastradas- y xalteatoctli - gravas arrastradas- (véase figura 1: 10-13). Al menos en el caso de xalatoctli existe una descripción en el Códice Florentino (Sahagún, 1963: 251, lib. 11) donde se dice que es arena arrastrada por el agua, muy suelta, y de porosa a muy porosa. Otro glifo cuyo significado está determinado por una acción se compone de una piedra, tetl, antropomorfa soplando lateralmente, ilpitza, pequeñas partículas o líneas que forman semiespirales por el elemento tentli - boca-. Se lee tepitzactli, que quiere decir "piedras delgadas" o "alargadas". El Códice Florentino (Sahagún, 1963: 266, lib. 11) describe un tipo de piedras llamadas tepitzactli, las cuales no tienen utilidad alguna.

El siguiente glifo, teuhtli - polvo- es similar aparentemente a tepitzactli, pero en realidad existen varias diferencias entre ambos (véase figura 1: 15). Teuhtli tiene al menos dos formas generales de escritura. Una primera se compone de una piedra en forma de "U" dando la apariencia de tener una "boca" amplia y sobre esta última se observan partículas que forman semiespirales. El confirmador de sonido para teuhtli se da con la forma en "U" estilizada y que alude a "pulque", uctli, ya que es análoga a las narigueras, símbolos, ornamentos y materiales de los dioses del pulque (Gonçalves de Lima, 1956). La segunda manera de escribir teuhtli es simplemente mediante una piedra, tetl, con las semiespirales de ehua sobre ella. 
Williams (1980: 56) detectó su significado con base en la glosa de nombres de personas dentro del cv y otros documentos nahuas, aunque no explicó la composición de sus elementos. Dos glifos idénticos a la primera forma aparecen en el CSMA como nombres personales de jefes de familia. En un caso, en el conjunto 4 del folio $34 \mathrm{r}$ sobre el glifo se lee "ju ${ }^{\circ}$. teuhtli". En un segundo caso, en el conjunto 4 del folio $30 \mathrm{r}$ el glifo fue trazado en conjunción con el elemento zacatl y por encima se lee "miguel tzacatehui".

Se lee teuhtli porque el glifo es de piedra, tetl, y proporciona el prefijo te, mientras que las semiespirales probablemente se refieren a ehua, u oeuh en pretérito, de "levantarse", "irse", o "emprender el vuelo" (Molina, 2001; Siméon, 1996: 150), es decir, que se eleva. Semiespirales similares aparecen también en nombres personales de individuos del CSMA (e.g. conjunto 1 folio $13 \mathrm{r}$ y conjunto 4 folio $37 \mathrm{r}$ ), aunque en estos casos su valor fonético es el de eca o eheca - viento, aire-. Sin embargo, me parece que, como

en el caso de atoctli, el mismo elemento tiene al menos estos dos valores fonéticos, cuya selección dependerá del contexto en el que se encuentren y su relación con otros elementos constitutivos. Al parecer, para el caso de elementos geológicos o del paisaje, en general se transcribe como ehua. El glifo teuhtli podría hacer referencia a terrenos polvorientos o secos (Sahagún, 1963: 255).

Similar a teuhtli y teçontli está el glifo compuesto por una piedra ensartada pero adicionalmente tiene por encima el elemento ehua - p. oeuh, levantarse, emprender el vuelo- (véase figura 1: 16). Probablemente se lee teçonectli, que significa "piedra esponjosa o ligera”. Aparece de manera esporádica en el CSMA. Un glifo más se compone de media piedra, tetl, en posición vertical con un fluido emanando o desbordándose sobre ella y cuyo valor fonético puede corresponder a çonehua o "crecer", "desbordarse", "erizarse" (Molina, 2001; Siméon, 1996). Sobre el fluido hay una serie de puntos elevándose y formando ganchos (véase figura 1: 17). Tomando como referencia elementos similares de nombres personales del CSMA (e.g., conjunto 1 del folio 45 r, conjunto 3 del f75, conjunto 1 folio 77v) los ganchos pueden leerse como eca o heca, que quiere decir "viento". En conjunto, el glifo podría leerse también como teçonectli o "piedra esponjosa o ligera". El elemento eca o viento estaría reforzando la idea de que se trata de un objeto airoso o liviano.

Otro glifo se compone de una piedra, tetl, rota, quebrándose, o desbaratándose, tlapactli (véase figura 1: 18). Se lee tetlapactli, que quiere decir "piedras rotas, estrelladas, o quebradas" o "pedazos de piedra" (Molina, 2001). Debe describir un terreno con piedras fragmentadas. En el conjunto 3 del folio $\mathrm{f} 17 \mathrm{r}$ del Csma hay un terreno sobre el cual atraviesa una corriente o extensión, toyaua, de agua, atl, es decir, un río o atoyatl (Siméon, 1996: 43) (véase figura 1: 19). Este tipo de elementos podían indicar la presencia de riego, pero en general son escasos. Otro glifo presente en el CSMA y en el FHVIII es el de zacatl o "paja, hierba, o junco" (véase figura 1:20). Comúnmente está acompañando a otros glifos, aunque también puede aparecer por sí solo. Zacatl podría estar aduciendo a terrenos con considerable maleza.

\section{Glifos toponímicos o locativos}

Un glifo locativo se compone del elemento ojo o rostro, ixtli, sobre un cerro, tepetl (véase figura 1:21). Dado que ixtli está encima del cerro, se debe añadir la partícula pan - sobre- para formar el sufijo ixpan, literalmente diciendo "sobre de" o "en la cara de". Gramaticalmente ixpan debe ir como sufijo del sustantivo, en este caso tepetl, por lo que el glifo se lee tepetlixpan o tepeixpan, que quiere decir "sobre o en la cara del cerro". El glifo es un locativo porque su configuración es similar a los toponímicos de otras fuentes (Berdan y Anawalt, 1992; Peñafiel, 1967). Además, dos Tepetlixpan son mencionados en los textos de Chimalpáhin, uno en Xochimilco y el otro en Chimalhuacan (Chimalpáhin, 1998: 153v., 180r.), 
incluso hoy día hay al menos dos poblaciones que presentan el mismo nombre. Tepetlixpan podría estar describiendo o localizando un terreno en las faldas de un cerro o en un paraje.

Un glifo que aparece en el FHVIII se compone de un árbol, quahuitl, sobre una olla, comitl, y ambos a su vez sobre el elemento "tlan" - abundante- (véase figura 1: 22). Seler (1904: 206) supuso que el glifo tenía dos significados. Por un lado, que el elemento árbol se unía a tlalli para formar quauhtlalli o tierra abonada con madera podrida, y por el otro que la olla unida a tlalli se refería a contlalli o tierra para hacer ollas. La lectura que encuentro más adecuada es que el árbol se refiere a un ocote - pino- - Uniendo los elementos se tiene ococotla u ocotla, en esta última comitl fungiendo como el confirmador de sonido. Quiere decir "lugar abundante en ocotes o pinos", es decir, un bosque de pinos.

\section{Glifos de elementos culturales}

Hay varios terrenos en el CSMA con un glifo formado por una piedra, tetl, alargada o extendida (véase figura 1: 23). La palabra en náhuatl para referirse a una tira o línea o cualquier forma similar es pantli. Al añadir el prefijo te de "piedra" se convierte en tepantli o "una línea de piedras", es decir, un "muro de piedras". Dado que se ubican en terrenos agrícolas, probablemente hace referencia a terrazas o linderos entre terrenos. Para facilitar su trazado, la figura de tepantli se dibujó como una tira y no piedra por piedra. En el CSMA hay dos glifos que quizá también pudieran referirse a tepantli y que sí fueron dibujados piedra por piedra. El Tipo 1 se compone de dos piedras, tetl, en hilera (véase figura 1: 24), mientras que el Tipo 2 se compone de tres piedras en hilera, una de ellas atravesada por una espina, ço, quizá para indicar un muro de piedras de tezontle, tezontli (véase figura 1:25).

Un elemento similar a tepantli aparece sólo en un terreno de la comunidad de Cuauhtepuztitla del CSMA. Tiene forma alargada y se trazó perpendicular al curso de una corriente de agua (véase figura 1:26).
Por encima se lee antzaqualli. Quizá el escribano cometió un error y en realidad debiera ser atzaqualli, de atl -agua-y tzaqua - contención o torre-, que literalmente quiere decir "contención de agua". La contención es de piedra porque presenta líneas verticales ondulantes para denotarla pero, para facilitar su trazado, también fue dibujada en forma alargada.

\section{Glifos de estatus o valor de la tierra}

Hay dos glifos que describen la condición de estatus o valor de un terreno. Uno procede del cv y se forma de una mazorca, cemolotl, sobre tlantli - dientes- y ambos a su vez sobre el elemento tlalli -tierra- (véase figura 1:27). Se lee tlacemolotlalli, que quiere decir "tierra heredada". El otro glifo procede del cx y aparece en dos terrenos asociados con chinampas en Culhuacan (Corona, 1989: 62). Se compone del elemento tlantli - dientes- atravesados por un auictli - remo- y ambos están sobre un círculo negro o tlilli (véase figura 1:28). Se lee tlaçotli, que significa "precioso y costoso" (Molina, 2001) o que refleja el valor de las chinampas agrícolas por su alta productividad.

Al contrario de las chinampas, un glifo del CSMA aduce a terrenos agotados o de mala calidad. Se componen de $i x t l i$-ojo, rostro, cara-, poctli - humo-y por encima ehua - p. oeuh, levantarse, emprender el vuelo- (véase figura 1:29). Podría leerse como ixpouhqui, que significa "pasado", "marchito", "ajado", o "decolorado" (Molina, 2001; Siméon, 1996: 223), es decir, un terreno empobrecido. Un glifo más se compone de petlatl —cama o estratoy sobre éste ehua - p. oeuh, levantarse, emprender el vuelo- (véase figura 1: 30 ). Tiene la misma estructura que teuhtli, sólo que en este caso la piedra es reemplazada por un petate. Se lee petlauhtli, que significa descubierto o descobijado, probablemente haciendo referencia a un terreno muy desprotegido o vulnerable a los elementos medioambientales (e. g. lluvia, heladas). 


\section{Glifos con el uso adicional del elemento petlatl}

El glifo de tepetlatl o "tepetate" ha sido particularmente estudiado por ser un término todavía utilizado en comunidades rurales. Como Williams (1972) lo ha señalado, la palabra se emplea para denominar a una gran variedad de tipos de suelos pedregosos y duros. En el csma y el cv el glifo se compone de una piedra, tetl, sobre una cama o estera, petlatl, para formar tepetlatl. Sin embargo, petlatl no es exclusivo para tepetate, ya que aparece combinado con otros elementos, como xalli - arena-, teuhtli - polvoo teçontli - tezontle- y se comporta más bien como un elemento añadido. Literalmente petlatl significa "estera" o "cama" (Siméon, 1996: 380), pero cuando se le añaden prefijos como tetl — piedra-o xalli - arena- parece adquirir un significado similar al de "capa" o "estrato". La idea es congruente con la manera en que se dibujó petlatl, ya que en general aparece por debajo de los demás elementos. Al comelementos adquiere coherencia. Existen al menos seis casos en los que petlatl está asociado a otros elementos, que son los siguientes (véase figura 1: 31-36):

1) Tetl + petlatl $=$ capa o estrato de piedras.

2) Teçontli + petlatl $=$ capa o estrato de tezontles.

3) Teuhtli + petlatl $=$ capa o estrato de polvo.

4) Xalli + petlatl $=$ capa o estrato de arena.

5) Xalteçontli + petlatl = capa o estrato de arena de tezontles.

6) Xaltetl + petlatl = capa o estrato de gravas de piedra.

\section{INTERPRETACIÓNY DISCUSIÓN DEL SIGNIFICADO DETRÁS DE LOS GLIFOS DE PARCELA}

Las fuentes etnohistóricas del siglo XVI muestran que los grupos nahuas del centro de México poseyeron un

complejo sistema clasificatorio y descriptivo de tierras y suelos (Williams, 2006) fuertemente asociado a los sistemas de manejo agrícola, incluyendo técnicas, tecnologías y herramientas asociadas (Rojas, 1984, 1988). Sin embargo, los llamados "glifos de suelo" en los códices aquí analizados no describen de manera exclusiva características edafológicas de los terrenos agrícolas. Su enfoque es más amplio, ya que también detallan elementos naturales y culturales del paisaje, como bosques, cerros, piedras y terrazas. Éste es un patrón muy similar a la notación de locativos presente en otros códices contemporáneos (e. g., la Matrícula de Tributos), en donde el nombre de las poblaciones corresponde a algún atributo particular de la zona.

Salvo en los casos de atoctli -aluvión-, xalli —arena-, xalatoctli —aluvión de arenas- y teuhlti - polvo-, que podrían referirse a aspectos edafológicos o etnopodológicos de un terreno, el resto de los glifos se refieren a componentes visibles en superficie o de alguna particularidad de estatus o valor que se le dio a la tierra (véase tabla 1). Técnicamente, podríamos asociar algunos glifos con calidades y cualidades de suelo, por ejemplo teuhtli con suelos limosos y secos, y tepetlatl con tierras escabrosas y duras. Pero el propósito original de los tlacuilos no parece haber sido tal, porque su sistema de registro se centró primordialmente en las particularidades de cada parcela, incluyendo variedades de suelos y rocas.

Por esta razón, un término más adecuado sería llamarlos "glifos de parcela", ya que detallan y engloban una variedad de características particulares de cada predio. Si los códices sirvieron para registrar las propiedades de un calpulli o un teccalli, de acuerdo con las prácticas legales de los indígenas (Zorita, 1942), los glifos de parcela, junto con los linderos y medidas proporcionadas, debieron fungir como marcadores de apoyo para tener un catastro eficiente. Con los glifos de parcela, incluyendo los datos sobre medidas, número de terrenos y sus dueños, se pudieron evitar confusiones en la identificación de predios similares y conflictos entre miembros del calpulli o entre distintas poblaciones. 
Tabla 1. Tipos de elementos o atributos registrados por los glifos de parcela

\begin{tabular}{|c|c|c|c|c|c|c|}
\hline $\begin{array}{l}\text { Elementos } \\
\text { culturales }\end{array}$ & $\begin{array}{c}\text { Elementos } \\
\text { naturales }\end{array}$ & Estatus o valor & \multicolumn{2}{|c|}{ Estratos, piedras o rocas } & Suelos & Toponímico \\
\hline $\begin{array}{c}\text { Atzaqualli } \\
\text { Tepantli } \\
\text { Teçonpantli }\end{array}$ & $\begin{array}{c}\text { Atoyatl } \\
\text { Zacatl }\end{array}$ & $\begin{array}{c}\text { Ixpouhqui } \\
\text { Petlauhtli } \\
\text { Tlacemolotlalli } \\
\text { Tlaçotli }\end{array}$ & $\begin{array}{c}\text { Teatoctli } \\
\text { Teçonatoctli } \\
\text { Teçonectli } \\
\text { Teçonpetlatl } \\
\text { Teçontli } \\
\text { Tepetlatl } \\
\text { Tepitzactli } \\
\text { Tetl } \\
\text { Tetla }\end{array}$ & $\begin{array}{c}\text { Tetlapactli } \\
\text { Teuhpetlatl } \\
\text { Xalpetlatl } \\
\text { Xalteatoctli } \\
\text { Xalteçonpetlatl } \\
\text { Xalteçontli } \\
\text { Xaltepetlatl } \\
\text { Xaltetl } \\
\text { Xalteyo }\end{array}$ & $\begin{array}{c}\text { Atoctla } \\
\text { Atoctli } \\
\text { Xalli } \\
\text { Xalatoctli } \\
\text { Teuhtli }\end{array}$ & $\begin{array}{c}\text { Tepetlixpan } \\
\text { Ocotla }\end{array}$ \\
\hline
\end{tabular}

La naturaleza descriptiva de los glifos de parcela pudo servir también para dar cuenta del tipo de recurso disponible (e. g., arena, árboles, piedras, tepetate) para cada familia y para todo el calpulli. El tributo fue parte fundamental de la encomienda $y$ aunque en comunidades como Santa María Asunción Tepetlaoztoc involucró principalmente alimentos y servicios (Hodge, 1991; Valle, 1992), es probable que incluso haya comprendido otros bienes, como madera y materias primas para la construcción u otras actividades artesanales. Saber quién poseía qué habría servido para que los nobles pudiesen extraer tributo de sus vasallos o renteros, función que después fue aprovechada por los encomenderos españoles durante la Colonia temprana.

Los glifos de parcela son muy estandarizados y más variados de lo que pensamos. Resulta interesante que algunos glifos del Csma y el $\mathrm{Cv}$, al igual que del Códice Florentino, describan palabras que ya no están en uso en el medio rural. El caso más llamativo son los glifos con la asociación del elemento petlatl, por ejemplo xaltepetlatl y teçonpetlatl. Además, las observaciones y registros sobre el entorno natural son bastante lógicas. Por ejemplo, sólo en las comunidades de Cuauhtepuztitla y Huiznahuac del CSMA aparecen glifos tepetlixpan indicando que los terrenos están en la ladera o encima del cerro. Es también ahí donde exclusivamente aparecen glifos de tepantli para indicar terrenos con terrazas. Es decir, hay una lógica en lo que se redacta: donde hay cerros hay terrazas. Es probable que otras sociedades complejas de Mesoamérica hubiesen tenido sistemas clasificatorios similares a los registros nahuas del siglo XVI, lo cual no resulta extraño considerando el alto grado de desarrollo técnico y tecnológico agrícola que tuvieron las poblaciones indígenas del siglo XVI (Rojas, 1988), sólo que por cuestiones históricas no existen registros al respecto.

Aunque el objetivo de este trabajo es el reanálisis de la lectura de los glifos, como resultado se encontró un dato adicional que discutiré brevemente. $\mathrm{Al}$ leer los glifos del CsMA y compararlos entre los registros milcocolli y tlahuelmatli encontré que hay fuertes discrepancias en el número, el tipo y la secuencia de los terrenos plasmados entre un registro y otro. Algunos errores de este tipo fueron detectados por Williams y Harvey (1997), pero no se les dio importancia. Sin embargo, con este trabajo dichos errores son más frecuentes y más obvios, en especial los relativos al orden y la concordancia de los terrenos registrados. Los terrenos asignados a un individuo en el milcocolli no siempre corresponden a los mismos que le aparecen asignados en el tlahuelmatli. Se podría argumentar que si bien el orden está mal, la totalidad de terrenos sí está presente. En realidad esto no sucede porque en muchos casos hay un desequilibrio en tipos de glifos representados entre los registros. 
Figura 2. Registros milcocolli -arriba-y tlahuelmatli -debajo-de Damiā Hecacoza y $\mathrm{P}^{\mathrm{o}}$.

Amoyotl de la comunidad de Tlaltecahuaca en el Códice de Santa María Asunción Tepetlaoztoc (f. 66r). Las palabras en recuadro corresponden a los glifos de parcela que concuerdan en nombre y área en los dos registros, 1997

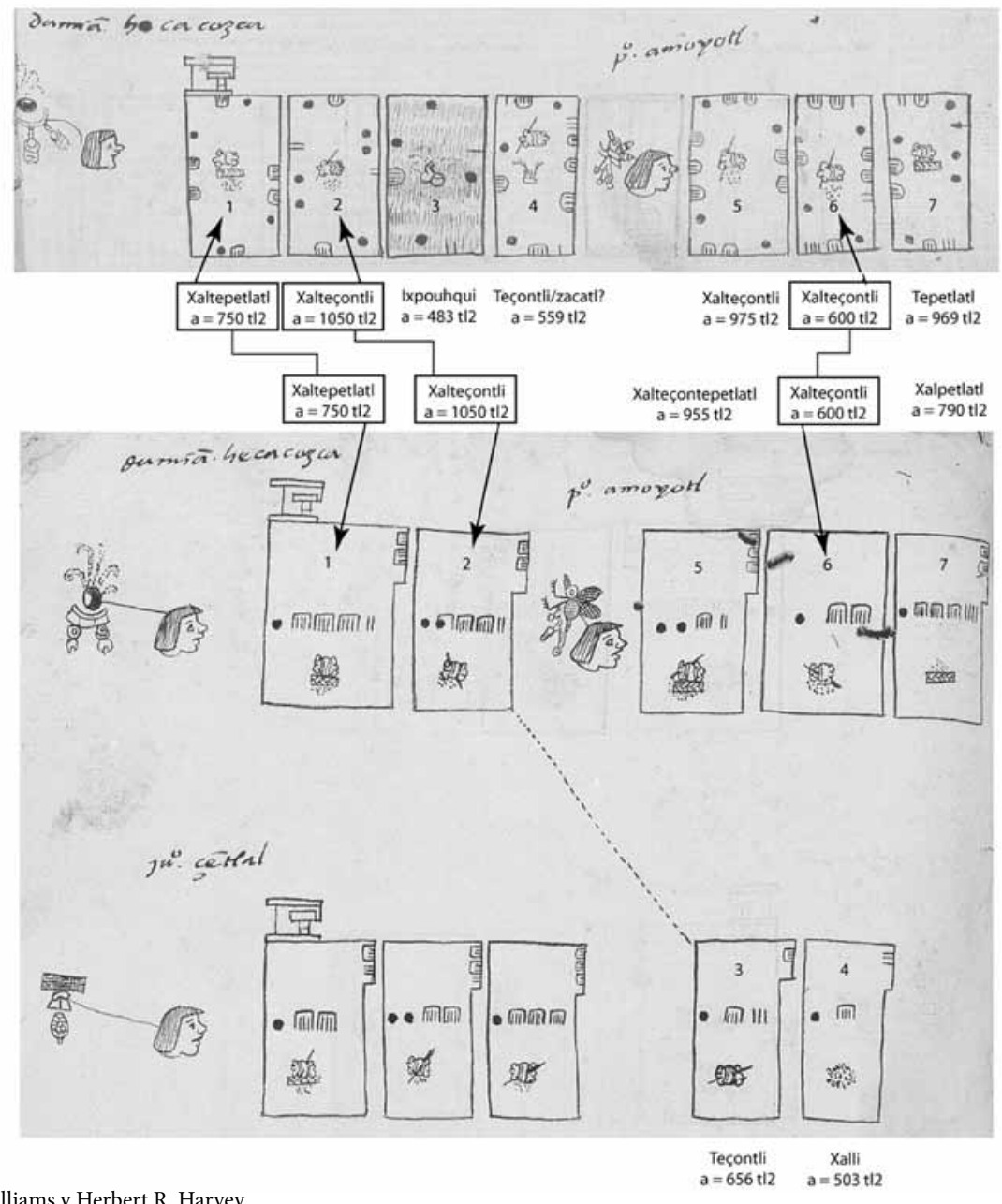

Fuente: Barbara J. Williams y Herbert R. Harvey.

Para mostrar este problema expongo el siguiente ejemplo. En la localidad de Tlaltecahuaca del csma (Williams y Harvey, 1997: 345, f. 66r) existe un grupo doméstico que tiene dos tributarios independientes con sus respectivos terrenos (véase figura 2). En el registro milcocolli el primer individuo, llamado Damiā Hecacozca, tiene cuatro campos con medidas y glifos de parcela, mientras que el segundo, llamado $\mathrm{P}^{\circ}$. Amoyotl, tiene tres. En la sección tlahuelmatli las mismas dos personas se presentan con el mismo número de terrenos y en el mismo orden. Sin embargo, los terrenos 3 y 4 de Damiā Hecacozca tienen diferentes glifos de parcela. Asimismo, los glifos sobre los terrenos 1 y 3 de Po. Amoyotl son diferentes. Para determinar si fueron errores de los tlacuilos se hizo el cálculo manual del área de los terrenos del milcocolli, siguiendo la aritmética descrita en Williams y Jorge y Jorge (2008), y se compararon los valores con las áreas registradas en el tlahuelmatli. El resultado es por demás sorprendente: los glifos que coinciden en 
denominación y orden de aparición también lo hacen perfectamente en área. Los campos con "errores" tienen nombres distintos y áreas disímiles.

La explicación más viable que encuentro, por el momento, es que los tlacuilos no cometieron errores, sólo registraron lo que observaban. Y lo que observaban no fue estático, cambió con el tiempo. Es decir, es probable que no siempre un mismo escribano redactara todos los censos de una comunidad y que los registros milcocolli y tlahuelmatli de cada comunidad fueran hechos en diferentes momentos, probablemente en distintos años. Una clave está en el estilo de trazado de los glifos, el cual suele variar entre registros de diferentes comunidades e incluso dentro de una misma. Si las propiedades fueron visitadas en diferentes años la tierra bien pudo haber cambiado de manos dependiendo del año en el que fueron censadas las familias. Es posible que los que parecen "errores" sean reflejo de cambios en la tenencia de la tierra, de movimiento de terrenos al interior del calpulli e incluso del sistema de manejo de los suelos mediante la rotación interanual de los terrenos agrícolas. Por ejemplo, se sabe que los líderes de calpulli distribuyeron las tierras de acuerdo con las necesidades de sus miembros y su disponibilidad, aunque no siempre equitativamente (López Austin, 1984; Zorita, 1942). Por ello, sería interesante y de gran utilidad refinar la secuencia temporal de manufactura de los registros de los códices de Santa María Asunción y el Vergara para comprender mejor la estructura interna y el manejo de los recursos de los calpulli o tlaxilacalli, en especial ante los fuertes cambios sociopolíticos y económicos introducidos durante la Colonia temprana.

\section{CONCLUSIÓN}

Este estudio se ha centrado en reanalizar la lectura de los glifos nahuas sobre las propiedades indígenas de cuatro códices acolhua de la Colonia temprana. El análisis concluye que hay más variación descriptiva en dichos glifos de lo que se pensaba y que no todos corresponden a una tipología de suelos porque más bien se enfocan en señalar atributos particulares de cada propiedad indígena. Por ello, es más conveniente llamarles "glifos de parcela" en el sentido de que son marcadores que probablemente debieron servir para llevar un catastro adecuado y para hacer la concordancia entre terrenos registrados en tiempos diferentes y por distintas personas.

\section{Referencias}

Berdan, Frances F. y Patricia Rieff Anawalt, 1992, The Codex Mendoza, University of California Press, Berkeley.

Calnek, Edward E., 1973, "The Localization of the Sixteenth Century Map Called The Maguey Map”, en American Antiquity, vol. XXXVIII, núm. 2, pp. 190-195.

Castañeda, María, 2006, "Un plano de tierras en el Códice Cozcatzin: adaptaciones y transformaciones de la cartografía prehispánica”, en Anales de Antropología, vol. XL, núm. 2, pp. 41-74.

Chimalpáhin, Domingo, 1998, Las ocho Relaciones y el Memorial de Colhuacan, Consejo Nacional para la Cultura y las Artes, México.

Corona, Eduardo, 1989, "La tenencia de la tierra en el Códice Xólotl", en Primer Coloquio de Documentos Pictográficos de Tradición Náhuatl, Universidad Nacional Autónoma de México, México, pp. 53-70.

Glass, John B., 1975, "A Survey of Native Middle American Pictorial Manuscripts", en Robert Wauchope y Howard F. Cline (eds.), Handbook of Middle American Indians: Guide to Ethnohistorical Sources, University of Texas Press, Austin, pp. 3-80.

Gonçalves de Lima, Oswaldo, 1956, El maguey y el pulque en los códices mexicanos, Fondo de Cultura Económica, México.

Harvey, Herbert R., 1986, "Household and Family Structure in Early Colonial Tepetlaoztoc: An Analysis of the Códice Santa María Asunción", en Estudios de la Cultura Náhuatl, núm. 18, pp. 275-294.

, 1991, "The Oztoticpac Lands Map: A Reexamination", en Land and Politics in the Valley of Mexico: A Two Thousand Year Perspective, University of New Mexico Press, Albuquerque, pp. 163-186.

Hodge, Mary G., 1991, "Land and Lordship in the Valley of Mexico: The Politics of Aztec Provincial Administration", en Herbert R. Harvey (ed.), Land and Politics in the Valley of Mexico: A Two Thousand Year Perspective, University of New Mexico Press, Albuquerque, p. 325. 
Karttunen, Frances E., 1983, An Analytical Dictionary of Nahuatl, University of Texas Press, Austin.

Lockhart, James, 2001, Nahuatl as Written: Lessons in Older Written Nahuatl, with Copious Examples and Texts, Stanford University Press, Stanford.

López Austin, Alfredo, 1984, Cuerpo humano e ideología: las concepciones de los antiguos nahuas, Universidad Nacional Autónoma de México, México.

Manrique Castañeda, Leonardo, 1989, "Ubicación de los documentos pictóricos de tradición náhuatl en una tipología de sistemas de registro y de escritura", en Primer Coloquio de Documentos Pictográficos de Tradición Náhuatl, Universidad Nacional Autónoma de México, México, pp. 159-170.

Mohar, Luz María y Rita Fernández, 2006, "El estudio de los códices: introducción y comentario", en Desacatos, núm. 22, pp. 9-22.

Molina, Fray Alonso de, 2001, Vocabulario en lengua castellana y mexicana, Ediciones de Cultura Hispánica, Madrid.

Nicholson, H. B., 1973, "Phonetism in the Late Pre-Hispanic Central Mexican Writing System”, en Elizabeth P. Benson (ed.), Mesoamerican Writing Systems: A Conference at Dumbarton Oaks, Dumbarton Oaks Research Library and Collections, Washington, D. C., pp. 1-46.

162 Offner, Jerome A., 1984, "Household Organization in the Texcocan Heartland: The Evidence in the Codex Vergara", en Herbert R. Harvey y Hanns J. Prem (eds.), Explorations in Ethnohistory: Indians of Central Mexico in the Sixteenth Century, University of New Mexico Press, Albuquerque, pp. 127-146.

Peñafiel, Antonio, 1967, Nombres geográficos de México: catálogo alfabético de los nombres de lugar pertenecientes al idioma "náhuatl", Secretaría de Fomento, Guadalajara.

Rojas, Teresa, 1984, "Agricultural Implements in Mesoamerica”, en Herbert R. Harvey y Hanns J. Prem (eds.), Explorations in Ethnohistory: Indians of Central Mexico in the Sixteenth Century, University of New Mexico Press, Albuquerque, pp. 175-204.

_ 1988 , Las siembras de ayer: la agricultura indígena del siglo XVI, Centro de Investigaciones y Estudios Superiores en Antropología Social, México.

Ross, Kurt, 1978, Codex Mendoza: Aztec Manuscript, Miller Graphics, Friburgo.

Sahagún, Bernardino de, 1963, Florentine Codex: General History of the Things of the New Spain, 12 vols., The School of American Research, The University of Utah, California.

Seler, Eduard, 1904, “The Mexican Picture Writings of Alexander Von Humboldt in the Royal Library at Berlin", en Mexican and Central American Antiquities,
Calendar Systems, and History, Bureau of American Ethnology, Washington, pp. 123-230.

Siméon, Rémi, 1996, Diccionario de la Lengua Náhuatl o Mexicana, Siglo XXI, México.

Sullivan, Thelma D., 1976, Compendio de la gramática náhuatl, Universidad Nacional Autónoma de México, México.

Thouvenot, Marc, 1992, "Nahuatl, informatique et TEMOA", en Amerindia, núm. 17, pp. 45-68.

, 1998, "Valeurs phoniques et unités de langue dans les glyphes des Codex Xolotl et Vergara", en Amerindia, núm. 23, pp. 67-97.

Valle, Perla, 1992, Memorial de los indios de Tepetlaoztoc o Códice Kingsborough «... A cuatrocientos cuarenta años», Instituto Nacional de Antropología e Historia, México.

Williams, Barbara J., 1972, "Tepetate in the Valley of Mexico", en Annals of the Association of American Geographers, vol. LXII, núm. 4, pp. 618-626.

- 1980, "Pictorial Representation of Soils in the Valley of Mexico: Evidence from the Codex Vergara", en Geoscience and Man, núm. 21, pp. 51-62.

_ 1989, "Contact Period Rural Overpopulation in the Basin of Mexico: Carrying-Capacity Models Tested with Documentary Data", en American Antiquity, vol. LIV, núm. 4, pp. 715-732.

, 2006, “Aztec Soil Knowledge: Classes, Management, and Ecology", en Benno P. Warkentin (ed.), Footprints in the Soil: People and Ideas in Soil History, Elsevier, Ámsterdam, pp. 17-42.

Williams, Barbara J. y Herbert R. Harvey, 1988, "Content, Provenience, and Significance of the Codex Vergara and the Códice de Santa María", en American Antiquity, núm. 53, p. 337.

- 1997, The Códice de Santa María Asunción: Households and Lands in Sixteenth-Century Tepetlaoztoc, University of Utah Press, Salt Lake City.

Williams, Barbara J. y María del Carmen Jorge y Jorge, 2001, "Surface Area Computation in Ancient Mexico: Documentary Evidence of Acolhua-Aztec Proto-Geometry", en Symmetry: Culture and Science, vol. XII, núm. 1-2, pp. 185-200.

, 2008, "Aztec Arithmetic Revisited: Land-Area Algorithms and Acolhua Congruence Arithmetic", en Science, vol. CCCXX, núm. 4, pp. 72-77.

Williams, Barbara J. y A. Ortiz-Solorio, 1981, "Middle American Folk Soil Taxonomy", en Annals of the Association of American Geographers, vol. LXXI, núm. 3, pp. 335-358.

Zorita, Alonso de, 1942, Breve y sumaria relación de los señores de la Nueva España, Universidad Nacional Autónoma de México, México. 